\title{
Molecular biology of normal melanocytes and melanoma cells
}

\author{
Bizhan Bandarchi, ${ }^{1} 2$ Cyrus Aleksandre Jabbari, ${ }^{3}$ Ali Vedadi, ${ }^{4}$ Roya Navab ${ }^{1}$
}

'Department of Applied Molecular Oncology, Princess Margaret Hospital, University of Toronto, Toronto, Ontario, Canada

${ }^{2}$ Department of Pathology, University of California, Los Angeles (UCLA), Los Angeles, California, USA

${ }^{3}$ American Specialty Laboratory, Los Angeles, California, USA

${ }^{4}$ Department of Laboratory Medicine and Pathobiology, University of Toronto, Toronto, Ontario, Canada

\section{Correspondence to} Dr Bizhan Bandarchi, Department of Applied Molecular Oncology, Princess Margaret Hospital, University of Toronto, 7 Concorde Place, Unit \# 2109, Toronto, Ontario, Canada M3C 3N4; bizhanb@yahoo.com

Received 14 January 2013 Revised 5 March 2013 Accepted 6 March 2013 Published Online First 23 March 2013

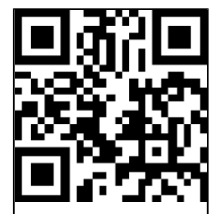

Editor's choice Scan to access mo free content

To cite: Bandarchi $B$, Jabbari CA, Vedadi A, et al. J Clin Pathol 2013:66 644-648.

\section{ABSTRACT}

Malignant melanoma is one of the most aggressive malignancies in humans and is responsible for $60-80 \%$ of deaths from skin cancers. The 5-year survival of patients with metastatic malignant melanoma is about $14 \%$. Its incidence has been increasing in the white population over the past two decades. The mechanisms leading to malignant transformation of melanocytes and melanocytic lesions are poorly understood. In developing malignant melanoma, there is a complex interaction of environmental and endogenous (genetic) factors, including: dysregulation of cell proliferation, programmed cell death (apoptosis) and cell-to-cell interactions. The understanding of genetic alterations in signalling pathways of primary and metastatic malignant melanoma and their interactions may lead to therapeutics modalities, including targeted therapies, particularly in advanced melanomas that have high mortality rates and are often resistant to chemotherapy and radiotherapy. Our knowledge regarding the molecular biology of malignant melanoma has been expanding. Even though several genes involved in melanocyte development may also be associated with melanoma cell development, it is still unclear how a normal melanocyte becomes a melanoma cell. This article reviews the molecular events and recent findings associated with malignant melanoma.

\section{MOLECULAR BIOLOGY OF NORMAL MELANOCYTES}

Melanocytes are pigment producing cells of the skin in humans and other vertebrates. ${ }^{1}$ Melanoma can occur in the oesophagus, meninges, oral mucosa, nasal cavity mucosa, anus/rectum, penis, vulva, vagina and conjunctiva, where the normal counterpart resides. ${ }^{2-4}$ Melanocytes originate from the neural crest with pluripotential cells that gradually become lineage specific during development. ${ }^{5} 6$ Following neural crest induction partly dependent on intact BMP signalling, ${ }^{7}$ neural crest stem cells undergo epithelial-mesenchymal transition (EMT) with loss of adhesion to neighbouring cells and eventually cell migration. In this process, Snail/Slug transcriptional factors repress E-cadherin expression and subsequent cell detachment and movement. ${ }^{8}$ Commitment of a pluripotential neural crest progenitor/stem cell to become a melanoblast, and eventually a mature melanocyte, involves Wnt (Wingless and a related gene termed int-1 in mice) signalling, which mediates a fate switch from glial-melanocyte lineage towards melanogenesis through $\beta$-catenin expression. ${ }^{6}{ }^{9-11}$ Several genes, including mitf (microphthalmia transcription factor), c-kit, snail/slug, sox10, and endothelins, which are important in melanocyte development, have been identified. ${ }^{1}$ By activating a few pigment-producing genes, including dct (dopachrome tautomerase) and tyrosinase, mitf gene regulates the melanocyte lineage. ${ }^{12}$ Melanocyte development, function, migration, and survival, depending on the species, are all dependent on expression of the tyrosine kinase receptor c-kit gene. ${ }^{13}$ Pigment machinery of the skin contains a complex set of reactions. ${ }^{14}$ Melanin pigment is produced by melanocytes within cytoplasmic melanosomes, in which tyrosinase acts on tyrosine and results in dopa and dopaquinone. ${ }^{15} 16$ Melanin pigment is transferred to an average of 36 adjacent keratinocytes and the key receptor in this transfer is protease-activated receptor 2 (PAR-2) on the keratinocytes' surface. ${ }^{17} 18$

\section{MOLECULAR BIOLOGY AND GENETIC ALTERATIONS IN MALIGNANT MELANOMA}

There are several endogenous and exogenous (environmental) risk factors associated with developing malignant melanoma, of which previous history of melanoma, family history of melanoma, and multiple dysplastic or benign (common/banal) nevi reveal the strongest association. ${ }^{19}$ Other risk factors include: long term sun exposure (probably intermittent exposure), tendency to burn easily and tan poorly, ultraviolet exposure (such as PUVA therapy), blond or red hair, pale skin, large congenital nevi, xeroderma pigmentosum, immunosuppression, scars, chemical exposures and Marjolin ulcers. ${ }^{20-28}$ To some degree, we know the association of these factors to the underlying molecular process. In all, $25-40 \%$ of malignant melanomas in a familial setting are associated with mutations in CDKN2A (cyclindependent kinase inhibitor $2 \mathrm{~A})^{29} 30$ and less commonly mutations in CDK4 (cyclin-dependent kinase 4). ${ }^{31}$ CDKN2A encodes two tumour suppressor proteins, p16 (INK4A/inhibitor of kinase 4A) and p14 (ARF/alternate reading frame), both involved in cell cycle regulation. ${ }^{32-34}$ Other genes, including MC1R (melanocortin-1 receptor) and DNA repair genes, are likely to be more important in determining the susceptibility for melanomas in the general population. ${ }^{35}$ Even though the results of the study conducted by Kanetsky $e t a l^{36}$ showed that MC1R is a low-penetrance susceptibility locus for melanoma as previously had been shown, their study did not show strong association between MC1R and melanoma, contrary to previous studies. PTEN/MMAC1 (phosphatase and tensin homologue/mutated in multiple advanced cancers 1) plays a central role in restricting cellular proliferation or promoting apoptosis. ${ }^{37}$ Tsao et al found high levels of PTEN expression in cutaneous muscle, nerve and muscular arteries, and moderate-to-high levels of PTEN in the 
epidermis, follicular epithelium, sebaceous and eccrine glands. They found uniformly strong PTEN in the cytoplasm in almost all benign and dysplastic nevi. They concluded that the presence of PTEN in benign melanocytic tumours and absence of PTEN in a significant proportion of primary cutaneous melanomas support a role of PTEN loss in the pathogenesis of malignant melanoma. ${ }^{37}$ Inactivating mutation of tumour suppressor gene, PTEN, is seen in $25-50 \%$ of non-familial melanomas. ${ }^{38-41}$ One of the most important genetic alterations in malignant melanoma involves receptor tyrosine kinases and the downstream NRAS/BRAF/ERK (neuroblastoma rat sarcoma/v-raf murine sarcoma homologue B/extracellular-related kinase) and phosphotidylinositol 3'-kinase (PI3K)/PTEN pathways. $^{42}$ Upregulation of MAPK (mitogenactivated protein kinase; Ras-Raf-MEK-ERK) and the phosphoinositide 3-kinase-AKT (also known as protein kinase $\mathrm{B} / \mathrm{PKB}$ ) pathways, both of which playing major roles in melanoma progression, are seen in a majority of malignant melanomas. ${ }^{43}{ }^{44}$ Lentigo maligna (solar melanoma) is associated with BRAF-activating (70\%) or NRAS-activating (20\%) mutations. In contrast, mucosal and acral melanoma lack mutations in both NRAS and BRAF. They are associated with mutations or genetic amplification of KIT (CD117) in up to $40 \%$ of cases. ${ }^{45}$ A6 Although benign nevi and malignant melanomas share initiation genetic alterations such as mutations in BRAF and NRAS, melanomas often show recurrent patterns of chromosomal losses (chromosomes $6 \mathrm{q}, 8 \mathrm{p}, 9 \mathrm{p}$ and $10 \mathrm{q})$, along with chromosomal gains (1q, 6p, 7, 8q, 17q and 20q) by comparative genomic hybridisation $(\mathrm{CGH})$ or karyotyping. Nevi, however, show no detectable chromosomal aberrations by CGH. ${ }^{19}{ }^{47-49}$ Gerami et al have recently developed a fluorescent in situ hybridisation (FISH) based test. By using four probes, this test targets three loci on chromosome 6 (RREB1 and MYB genes) and one locus on chromosome 11 (cyclin D1 gene). This method of testing that is applicable to formalin-fixed paraffin-embedded tissue is claimed to have the most powerful discriminatory ability to differentiate between nevi and malignant melanomas. ${ }^{50} 51$ Piepkorn ${ }^{52}$ showed that expression of p16 (INK4A) is upregulated in human melanocytes by ultraviolet $\mathrm{B}$ irradiation. Alterations in cell cycle proteins cyclin $\mathrm{D} 1, \mathrm{pRb}$ and $\mathrm{p} 16$ have a role in transformation and progression in melanocytic tumours. Even though there is an increase in expression of $\mathrm{pRb}$ and cyclin $\mathrm{D} 1$ in the progression to melanoma cells, these two cell cycle proteins interestingly reveal a relative decrease in thick and metastatic malignant melanoma. Progressive loss of p16 is seen in transformation of benign nevi to melanoma and metastatic melanoma. ${ }^{53}$ Upregulation of PAR-1 (protease-activated receptor-1) mediates high levels of Cx-43 (connexin molecule), involved in tumour cell diapedesis and attachment to endothelial cells. ${ }^{54}$ Type I collagenase and PAR-1 activating functions of MMP-1 (matrix metalloproteinase-1) are required for melanoma progression. Blackburn et $a l^{55}$ have suggested that highly expressed MMP-1 is involved in progression of non-invasive melanoma to an invasive vertical growth phase by degrading type I collagen of skin.

MCSP (melanoma chondroitin sulfate proteoglycan/human melanoma proteoglycan) and rat homologous NG2 are transmembrane proteoglycans in which the core protein is modified with chondroitin sulfate. ${ }^{56-58}$ Normal melanocytes express little or no MCSP in situ. Increased levels of MCSP are seen in benign and dysplastic nevi. ${ }^{56}$ MCSP expression in acral lentiginous malignant melanoma is associated with poorer prognosis. $^{59} 60$ MCSP expression is also seen in association with increased c-Met and HGF. Inhibition of c-Met limits the growth and motility of melanoma cells in melanoma cell lines. ${ }^{60}$ Mutant active BRAF in melanomas is associated with a high level of constitutive activation of Erk1,2. ${ }^{61}$ Results of the sustained activation of the Erk1,2 pathway include: entry into the cell cycle, increased expression of key melanoma transcription factors, and other important factors for invasion, such as matrix metalloproteinases. By increasing the expression of specific integrin subunits (such as $\beta 3$ ) and elevated resistance to apoptosis, Erk1,2 activation causes increased adhesion. ${ }^{43}$

There is evidence revealing that miRNAs are deregulated during melanoma progression. ${ }^{62}{ }^{63}$ Frequent dysregulation of miRNA expression in lymph node metastasis of melanomas has been reported in association with patient survival and mutational status. There are also findings which show differential expression of miRNA in melanomas in comparison to melanocytes. Caramuta et al found that ectopic expression of miRNA-182 promotes lung metastasis in a mouse model. High and low expression of miRNA-193b and miRNA-191, respectively, are significantly associated with poor survival. Low expression of miRNA-193a, miRNA-338 and miRNA-565 is associated with cases of BRAF missense mutation, and low expression of miRNA-663 is associated with NRAS-mutated cases. However, no significant differentially expressed miRNA was found between BRAF versus NRAS mutated melanomas. ${ }^{64}$ It has been shown that high expression of miRNA-193b is associated with a high risk of metastasis in uveal melanoma. ${ }^{65}$

Based on the fact that angiogenesis is one of the most important factors needed for melanoma progression and metastasis, Mehnert et al showed that expression of vascular endothelial growth factor (VEGF) and its receptors (VEGF-R1, VEGF-R2, VEGF-R3) is higher in melanomas and advanced melanomas than in benign nevi. VEGF-R2 shows higher expression in metastatic melanomas than in primary melanomas. In contrast, higher expression of VEGF-R3 is seen in primary lesions, supporting the fact that VEGF-R3 is involved in initiation of lymphatic tumour spread. ${ }^{66}$

Downregulation and upregulation of E-cadherin and $\mathrm{N}$-cadherin respectively may be seen in melanoma. This shift in cadherin profiles may play a role in uncontrolled proliferation, invasion and migration of melanoma cells. ${ }^{67}$

Remodelling of actin cytoskeleton is essential for tumour cell invasion and metastasis. Altered expression of actin cytoskeleton components may also have some role in transformation and tumourigenesis. $^{68} 69$ Immunohistochemical study on human tissue samples has shown there is a significantly higher cortactin expression in melanoma than nevi and in metastatic melanoma than invasive primary melanoma. ${ }^{70}$ Cortactin is a multidomain actin-binding protein involved in endocytosis, cell migration, invasion and adhesion. ${ }^{71-73}$

Protein kinase $\mathrm{C}(\mathrm{PKC})$ is activated by diacylglycerol and mediates pathway signals for cell growth and proliferation. PKC is a target of tumour-promoting phorbol esters in malignant transformation. $^{74}$

Sviatoha et al analysed immunohistochemical expression of the S100A1, S100m, CD44 and Bcl-2 antigens, whose involvement in transformation of melanocytes to melanoma cells has been described. S100 is a dimeric protein composed of $\alpha$ and $\beta$ subunits that regulates the assembly of cytoskeletal systems of cells such as filaments and microtubules. S100 has been suggested to be involved in cell cycle regulation, division and cell-to-cell communications. ${ }^{75}{ }^{76}$ One study showed high expression of S100A1 in malignant melanocytic proliferation of conjunctiva. ${ }^{77}$ S100B interacts with p53 tumour suppressor protein and downregulates its function. ${ }^{78}$ Sviatoha et al also showed that S100B expression in dysplastic nevi is similar to acquired (banal) nevi, whereas expression of S100A1 tends to be higher. In primary and metastatic melanomas there is a 
decrease in expression of $\mathrm{S} 100 \mathrm{~B}$ and increased expression of S100A1. Even though S100 expression in melanoma is decreased, this expression is higher in areas with increased proliferation. ${ }^{79} \mathrm{CD} 44$, an adhesion molecule and a family of transmembrane glycoproteins that is a main ligand for hyaluronic acid, is involved in cell growth signal transmission, cell adhesion to endothelium, cell migration and increased cell motility. ${ }^{80} 81$ CD44 protein is upregulated during melanoma progression. ${ }^{81}$ CD44 reveals marked variation in the expression of nevi and melanomas. The same study also showed that in metastatic melanoma, the mean number of CD44 cell fraction was higher in melanoma without metastasis, even though no significant correlation between CD44 protein expression and various histopathological characteristics was seen. ${ }^{79} \mathrm{Bcl}-2$ proto-oncogene, located on chromosome 18, is involved in regulation of apoptosis (programmed cell death). ${ }^{82}{ }^{83} \mathrm{Bcl}-2$ expression is higher in nevi than melanomas. ${ }^{79}$

Interaction of E2F1 transcription factor with RGFR may act as a driving force in melanoma progression. ${ }^{84}$

There is abnormal expression of major histocompatibility complex (MHC) molecules in melanomas. In the vertical growth phase of melanoma, there is an increased DNA copy number gain of MHC genes, along with increased expression compared to normal melanocytes. However, MHC expression in metastatic melanoma is decreased in comparison to vertical growth phase melanoma, and yet there is still increased DNA copy number gain. In earlier stages of malignant melanoma, there is over-expression of MHC molecules, in contrast to its downregulation in metastatic melanoma. ${ }^{85}$

Loss of pigment epithelium-derived factor (PEDF) is associated with malignant progression and invasion in melanoma. ${ }^{86}$ CXCR1 and CXCR2 chemokines receptors and their ligands are important players in the pathogenesis of malignant melanoma. CXCR1 is constitutively expressed in all melanomas irrespective of their stage and grade. CXCR2 expression, however, is limited to aggressive melanomas. It has been shown that modulation of CXCR1 and CXCR2 expression and/or activity regulate malignant melanoma growth, angiogenesis and metastasis. ${ }^{87-89}$

ATP-binding cassette $(\mathrm{ABC})$ transporters regulate the transportation of various physiological substances across biological membranes. ${ }^{90} \mathrm{ABC}$ transporters' high expression levels have been seen in various malignant tumours, including ovarian carcinoma, lung carcinoma, osteosarcoma and neuroblastoma. ABC transporter mRNA expression profile and differentially regulated $\mathrm{ABC}$ transporters are candidate genes involved in malignant melanoma tumourigenesis, progression and treatment resistance. $^{91}$

The SOX (sex determining region Y-box) family of transcription factors is involved in the development of normal physiology of numerous tissues including melanocytes. SOX5, SOX9, SOX10 and SOX18 transcription factors affect the key modulatory and regulatory melanocytic genes. This regulation of SOX9 or SOX10 is associated with cancerous transformation. ${ }^{92}$

Heparin and its derivatives can inhibit angiogenesis and metastasis. Kenessey et $a l^{93}$ have shown that fragments of heparin, not involved in haemostasis, may play a role in antimigratory and antimetastatic processes.

Until recently, available strategies on systemic therapy of advanced malignant melanoma have been limited ${ }^{94}$ and have shown only a minimal effect on patient survival. A phase III trial treatment with oral BRAF inhibitor vemurafenib showed significant improvement in both progression-free survival as well as overall survival over chemotherapy. ${ }^{95}$
Even though it is still not completely clear how a normal melanocyte becomes a melanoma cell, the rapid pace of discovering more and more pathways, genetic alterations, and understanding the biology of malignant melanoma in the 'molecular era' are definitely paving the road for finding more specific therapeutic modalities and developing novel targeted therapies.

Contributors BB conceived the idea for the manuscript. RN, CAJ and AV were responsible for designing, writing and critically revising the initial draft. All authors read and have approved the final manuscript.

Competing interests None.

Provenance and peer review Not commissioned; internally peer reviewed.

\section{REFERENCES}

1 Uong A, Zon LI. Melanocytes in development and cancer. J Cell Physiol 2010:222:38-41.

2 Larsson KB, Shaw HM, Thompson JF, et al. Primary mucosal and glans penis melanomas: the Sydney Melanoma Unit experience. Aust N Z J Surg 1999:69:121-6

3 Oliva E, Quinn TR, Amin MB, et al. Primary malignant melanoma of the urethra: a clinicopathologic analysis of 15 cases. Am J Surg Pathol 2000;24:785-96.

4 Pandey M, Mathew A, Abraham EK, et al. Primary malignant melanoma of the mucous membranes. Eur J Surg Oncol 1998;24:303-7.

5 Erickson CA, Reedy MV. Neural crest development: the interplay between morphogenesis and cell differentiation. Curr Top Dev Biol 1998:40:177-209.

6 Dorsky RI, Moon RT, Raible DW. Control of neural crest cell fate by the Wnt signalling pathway. Nature 1998;396:370-3

7 Kanzler B, Foreman RK, Labosky PA, et al. BMP signaling is essential for development of skeletogenic and neurogenic cranial neural crest. Development 2000;127:1095-104.

8 Cano A, Perez-Moreno MA, Rodrigo I, et al. The transcription factor snail controls epithelial-mesenchymal transitions by repressing E-cadherin expression. Nat Cell Biol 2000;2:76-83.

9 Dupin E, Glavieux C, Vaigot $P$, et al. Endothelin 3 induces the reversion of melanocytes to glia through a neural crest-derived glial-melanocytic progenitor. Proc Natl Acad Sci USA 2000;97:7882-7.

10 Ikeya $M$, Lee $S M$, Johnson JE, et al. Wnt signalling required for expansion of neural crest and CNS progenitors. Nature 1997;389:966-70.

11 Dunn KJ, Williams BO, Li Y, et al. Neural crest-directed gene transfer demonstrates Wnt1 role in melanocyte expansion and differentiation during mouse development. Proc Natl Acad Sci USA 2000;97:10050-5.

12 Yasumoto K, Yokoyama K, Shibata K, et al. Microphthalmia-associated transcription factor as a regulator for melanocyte-specific transcription of the human tyrosinase gene. Mol Cell Biol 1994;14:8058-70.

13 Wehrle-Haller B, Weston JA. Soluble and cell-bound forms of steel factor activity play distinct roles in melanocyte precursor dispersal and survival on the lateral neural crest migration pathway. Development 1995;121:731-42.

14 Grichnik JM, Burch JA, Burchette J, et al. The SCF/KIT pathway plays a critical role in the control of normal human melanocyte homeostasis. J Invest Dermatol 1998:111:233-8

15 Hearing VJ, Jimenez M. Analysis of mammalian pigmentation at the molecular level Pigment Cell Res 1989:2:75-85.

16 Naeyaert JM, Eller M, Gordon PR, et al. Pigment content of cultured human melanocytes does not correlate with tyrosinase message level. $\mathrm{Br} J$ Dermatol 1991;125:297-303.

17 Bolognia JL, Pawelek JM. Biology of hypopigmentation. J Am Acad Dermatol 1988; 19:217-55

18 Hermanns JF, Petit L, Martalo O, et al. Unraveling the patterns of subclinical pheomelanin-enriched facial hyperpigmentation: effect of depigmenting agents. Dermatology 2000;201:118-22.

19 Bandarchi LM Bizhan, Navab R, Seth A, et al. From melanocyte to metastatic malignant melanoma. Dermatology Research and Practice [serial on the Internet]. 2010; 2010. http://www.hindawi.com/journals/drp/2010/583748.html.

20 Katsambas A, Nicolaidou E. Cutaneous malignant melanoma and sun exposure. Recent developments in epidemiology. Arch Dermatol 1996:132:444-50.

21 Beral V, Evans $S$, Shaw $H$, et al. Cutaneous factors related to the risk of malignant melanoma. Br J Dermatol 1983;109:165-72.

22 Whiteman DC, Green AC. Melanoma and sun exposure: where are we now? Int J Dermatol 1999;38:481-9.

23 Beitner $\mathrm{H}$, Ringborg U, Wennersten $\mathrm{G}$, et al. Further evidence for increased light sensitivity in patients with malignant melanoma. Br J Dermatol 1981;104:289-94.

24 Schneider JS, Moore DH II, Sagebiel RW. Risk factors for melanoma incidence in prospective follow-up. The importance of atypical (dysplastic) nevi. Arch Dermatol 1994:130:1002-7. 
25 Lee JY, Kapadia SB, Musgrave RH, et al. Neurotropic malignant melanoma occurring in a stable burn scar. J Cutan Pathol 1992;19:145-50.

26 Rockley PF, Trieff N, Wagner RF Jr, et al. Nonsunlight risk factors for malignan melanoma. Part I: Chemical agents, physical conditions, and occupation. Int J Dermatol 1994;33:398-406.

27 Gan BS, Colcleugh RG, Scilley CG, et al. Melanoma arising in a chronic (Marjolin's) ulcer. J Am Acad Dermatol 1995:32:1058-9.

28 Merkle $\mathrm{T}$, Landthaler $\mathrm{M}, \mathrm{Eckert} \mathrm{F}$, et al. Acral verrucous malignant melanoma in an immunosuppressed patient after kidney transplantation. J Am Acad Dermatol 1991:24:505-6.

29 Aitken J, Welch J, Duffy D, et al. CDKN2A variants in a population-based sample of Queensland families with melanoma. J Natl Cancer Inst 1999:91:446-52.

30 Bataille V. Genetics of familial and sporadic melanoma. Clin Exp Dermatol 2000:25:464-70.

31 Nagore E, Climent J, Planelles MD, et al. Analysis of the CDKN2A and CDK4 genes and HLA-DR and HLA-DQ alleles in two Spanish familial melanoma kindreds. Acta Dermatol Venereol 2000;80:440-2.

32 Berwick M, Orlow I, Hummer AJ, et al. The prevalence of CDKN2A germ-line mutations and relative risk for cutaneous malignant melanoma: an international population-based study. Cancer Epidemiol Biomarkers Prev 2006;15:1520-5.

33 Kamb A, Gruis NA, Weaver-Feldhaus J, et al. A cell cycle regulator potentially involved in genesis of many tumor types. Science 1994;264:436-40.

34 Nobori T, Miura K, Wu DJ, et al. Deletions of the cyclin-dependent kinase-4 inhibitor gene in multiple human cancers. Nature 1994;368:753-6.

35 Bataille V. Genetic epidemiology of melanoma. Eur J Cancer 2003;39:1341-7.

36 Palmer JS, Duffy DL, Box NF, et al. Melanocortin-1 receptor polymorphisms and risk of melanoma: is the association explained solely by pigmentation phenotype? Am J Hum Genet 2000;66:176-86.

37 Tsao H, Mihm MC Jr, Sheehan C. PTEN expression in normal skin, acquired melanocytic nevi, and cutaneous melanoma. J Am Acad Dermatol 2003;49:865-72

38 Flores JF, Walker GJ, Glendening JM, et al. Loss of the p16INK4a and p15INK4b genes, as well as neighboring 9p21 markers, in sporadic melanoma. Cancer Res 1996:56:5023-32.

39 Wu H, Goel V, Haluska FG. PTEN signaling pathways in melanoma. Oncogene 2003:22:3113-22

40 Li J, Yen C, Liaw D, et al. PTEN, a putative protein tyrosine phosphatase gene mutated in human brain, breast, and prostate cancer. Science 1997:275:1943-7.

41 Steck PA, Pershouse MA, Jasser SA, et al. Identification of a candidate tumour suppressor gene, MMAC1, at chromosome 10q23.3 that is mutated in multiple advanced cancers. Nat Genet 1997;15:356-62.

42 Goel VK, Lazar AJ, Warneke $C L$, et al. Examination of mutations in BRAF, NRAS, and PTEN in primary cutaneous melanoma. J Invest Dermatol 2006;126:154-60.

43 Smalley KS. A pivotal role for ERK in the oncogenic behaviour of malignant melanoma? Int J Cancer 2003;104:527-32.

44 Dhawan $P$, Singh $A B$, Ellis $D L$, et al. Constitutive activation of Akt/protein kinase $B$ in melanoma leads to up-regulation of nuclear factor-kappaB and tumor progression. Cancer Res 2002;62:7335-42.

45 Curtin JA, Busam K, Pinkel D, et al. Somatic activation of KIT in distinct subtypes of melanoma. J Clin Oncol 2006;24:4340-6

46 Curtin JA, Fridlyand J, Kageshita T, et al. Distinct sets of genetic alterations in melanoma. N Engl J Med 2005;353:2135-47.

47 Bastian $B C$, Olshen $A B$, LeBoit $P E$, et al. Classifying melanocytic tumors based on DNA copy number changes. Am J Pathol 2003;163:1765-70.

48 Cowan JM, Halaban R, Francke U. Cytogenetic analysis of melanocytes from premalignant nevi and melanomas. J Nat/ Cancer Inst 1988;80:1159-64.

49 Greulich KM, Utikal J, Peter RU, et al. c-MYC and nodular malignant melanoma. A case report. Cancer 2000;89:97-103.

50 Gerami P, Jewell SS, Morrison LE, et al. Fluorescence in situ hybridization (FISH) as an ancillary diagnostic tool in the diagnosis of melanoma. Am J Surg Pathol 2009;33:1146-56.

51 Morey AL, Murali R, McCarthy SW, et al. Diagnosis of cutaneous melanocytic tumours by four-colour fluorescence in situ hybridisation. Pathology 2009;41:383-7.

52 Piepkorn $\mathrm{M}$. The expression of $\mathrm{p16}$ (INK4a), the product of a tumor suppressor gene for melanoma, is upregulated in human melanocytes by UVB irradiation. J Am Acad Dermatol 2000;42(5 Pt 1):741-5.

53 Karim RZ, Li W, Sanki A, et al. Reduced p16 and increased cyclin D1 and pRb expression are correlated with progression in cutaneous melanocytic tumors. Int $J$ Surg Pathol 2009:17:361-7.

54 Villares GJ, Dobroff AS, Wang H, et al. Overexpression of protease-activated receptor-1 contributes to melanoma metastasis via regulation of connexin 43. Cancer Res 2009;69:6730-7.

55 Blackburn JS, Liu I, Coon Cl, et al. A matrix metalloproteinase-1/protease activated receptor- 1 signaling axis promotes melanoma invasion and metastasis. Oncogene 2009:28:4237-48.

56 Campoli MR, Chang CC, Kageshita T, et al. Human high molecular weight-melanoma-associated antigen (HMW-MAA): a melanoma cell surface chondroitin sulfate proteoglycan (MSCP) with biological and clinical significance. Crit Rev Immunol 2004;24:267-96.

57 Chekenya M, Rooprai HK, Davies D, et al. The NG2 chondroitin sulfate proteoglycan: role in malignant progression of human brain tumours. Int J Dev Neurosci 1999:17:421-35.

58 Stallcup WB. The NG2 proteoglycan: past insights and future prospects. J Neurocytol 2002;31:423-35.

59 Kageshita T, Nakamura T, Yamada M, et al. Differential expression of melanoma associated antigens in acral lentiginous melanoma and in nodular melanoma lesions. Cancer Res 1991:51:1726-32.

60 Yang J, Price MA, Li GY, et al. Melanoma proteoglycan modifies gene expression to stimulate tumor cell motility, growth, and epithelial-to-mesenchymal transition. Cancer Res 2009;69:7538-47.

61 Houben R, Becker JC, Kappel A, et al. Constitutive activation of the Ras-Raf signaling pathway in metastatic melanoma is associated with poor prognosis. J Carcinog 2004;3:6.

62 Gaur A, Jewell DA, Liang Y, et al. Characterization of microRNA expression levels and their biological correlates in human cancer cell lines. Cancer Res 2007:67:2456-68.

63 Mueller DW, Rehli M, Bosserhoff AK. miRNA expression profiling in melanocytes and melanoma cell lines reveals miRNAs associated with formation and progression of malignant melanoma. J Invest Dermatol 2009;129: 1740-51.

64 Caramuta S, Egyhazi S, Rodolfo M, et al. MicroRNA expression profiles associated with mutational status and survival in malignant melanoma. J Invest Dermatol 2010;130:2062-70

65 Worley LA, Long MD, Onken MD, et al. Micro-RNAs associated with metastasis in uveal melanoma identified by multiplexed microarray profiling. Melanoma Res 2008;18:184-90.

66 Mehnert JM, McCarthy MM, Jilaveanu L, et al. Quantitative expression of VEGF, VEGF-R1, VEGF-R2, and VEGF-R3 in melanoma tissue microarrays. Hum Pathol 2010;41:375-84

67 Hsu MY, Wheelock MJ, Johnson KR, et al. Shifts in cadherin profiles between human normal melanocytes and melanomas. J Invest Dermato/ Symp Proc 1996;1:188-94

68 Yamaguchi $\mathrm{H}$, Condeelis J. Regulation of the actin cytoskeleton in cancer cell migration and invasion. Biochim Biophys Acta 2007;1773:642-52.

69 Pawlak G, Helfman DM. Cytoskeletal changes in cell transformation and tumorigenesis. Curr Opin Genet Dev 2001:11:41-7.

70 Xu XZ, Garcia MV, Li TY, et al. Cytoskeleton alterations in melanoma: aberrant expression of cortactin, an actin-binding adapter protein, correlates with melanocytic tumor progression. Mod Pathol 2010;23:187-96

71 Weed SA, Parsons JT. Cortactin: coupling membrane dynamics to cortical actin assembly. Oncogene 2001;20:6418-34.

72 Weaver AM. Cortactin in tumor invasiveness. Cancer Lett 2008:265:157-66.

73 Ammer AG, Weed SA. Cortactin branches out: roles in regulating protrusive actin dynamics. Cell Motil Cytoskeleton 2008:65:687-707.

74 Oka M, Kikkawa U. Protein kinase C in melanoma. Cancer Metastasis Rev 2005:24:287-300.

75 Singh $\mathrm{P}$, Wong $\mathrm{SH}$, Hong $\mathrm{W}$. Overexpression of E2F-1 in rat embryo fibroblasts leads to neoplastic transformation. EMBO J 1994;13:3329-38

76 Xu G, Livingston DM, Krek W. Multiple members of the E2F transcription factor family are the products of oncogenes. Proc Natl Acad Sci USA 1995:92:1357-61.

77 Frame FM, Rogoff HA, Pickering MT, et al. E2F1 induces MRN foci formation and a cell cycle checkpoint response in human fibroblasts. Oncogene 2006;25:3258-66.

78 Rabbani F, Richon VM, Orlow I, et al. Prognostic significance of transcription factor E2F-1 in bladder cancer: genotypic and phenotypic characterization. J Nat/ Cancer Inst 1999:91:874-81.

79 Sviatoha $\mathrm{V}$, Tani $\mathrm{E}$, Kleina $\mathrm{R}$, et al. Immunohistochemical analysis of the S100A1, $\mathrm{S} 100 \mathrm{~B}, \mathrm{CD} 44$ and $\mathrm{BCl}-2$ antigens and the rate of cell proliferation assessed by Ki-67 antibody in benign and malignant melanocytic tumours. Melanoma Res 2010;20:118-25.

80 Gorgoulis VG, Zacharatos P, Mariatos G, et al. Transcription factor E2F-1 acts as a growth-promoting factor and is associated with adverse prognosis in non-small cell lung carcinomas. J Pathol 2002;198:142-56.

81 Imai MA, Oda Y, Oda M, et al. Overexpression of E2F1 associated with LOH at RB locus and hyperphosphorylation of RB in non-small cell lung carcinoma. J Cancer Res Clin Oncol 2004;130:320-6.

82 Zacharatos $\mathrm{P}$, Kotsinas A, Evangelou K, et al. Distinct expression patterns of the transcription factor $\mathrm{E} 2 \mathrm{~F}-1$ in relation to tumour growth parameters in common human carcinomas. J Pathol 2004;203:744-53.

83 Salon C, Merdzhanova G, Brambilla C, et al. E2F-1, Skp2 and cyclin E oncoproteins are upregulated and directly correlated in high-grade neuroendocrine lung tumors. Oncogene 2007:26:6927-36.

84 Alla V, Engelmann D, Niemetz A, et al. E2F1 in melanoma progression and metastasis. J Natl Cancer Inst 2010;102:127-33. 
85 Degenhardt Y, Huang J, Greshock J, et al. Distinct MHC gene expression patterns during progression of melanoma. Genes Chromosomes Cancer 2010;49: 144-54.

86 Orgaz JL, Ladhani O, Hoek KS, et al. Loss of pigment epithelium-derived factor enables migration, invasion and metastatic spread of human melanoma. Oncogene 2009;28:4147-61.

87 Sharma B, Singh S, Varney ML, et al. Targeting CXCR1/CXCR2 receptor antagonism in malignant melanoma. Expert Opin Ther Targets 2010;14:435-42.

88 Vandercappellen J, Van Damme J, Struyf S. The role of CXC chemokines and their receptors in cancer. Cancer Lett 2008;267:226-44.

89 Richmond A, Yang J, Su Y. The good and the bad of chemokines/chemokine receptors in melanoma. Pigment Cell Melanoma Res 2009:22:175-86.

90 Dean $M$, Allikmets R. Complete characterization of the human $A B C$ gene family. J Bioenerg Biomembr 2001;33:475-9.
91 Heimerl S, Bosserhoff AK, Langmann T, et al. Mapping ATP-binding cassette transporter gene expression profiles in melanocytes and melanoma cells. Melanoma Res 2007;17:265-73.

92 Harris ML, Baxter LL, Loftus SK, et al. Sox proteins in melanocyte development and melanoma. Pigment Cell Melanoma Res 2010;23:496-513.

93 Kenessey I, Simon E, Futosi K, et al. Antimigratory and antimetastatic effect of heparin-derived 4-18 unit oligosaccharides in a preclinical human melanoma metastasis model. Thromb Haemost 2009;102:1265-73.

94 Koren EL, Liu PY, Lee SJ, et al. Metanalysis of phase II cooperative group trials in metastatic stage IV melanoma to determine progression-free and overall survival benchmarks for future phase II trials. J Clin Oncol 2008;26:527-34.

95 Sosman JA, Kim KB, Schuchter $L$, et al. Survival in BRAF V600-mutant advanced melanoma treated with vemurafenib. N Engl J Med 2012;366:707-14. 